\title{
DESEMPENHO NARRATIVO EM SUJEITOS COM DISTÚRBIO/ATRASO FONOLÓGICO
}

\section{Narrative performance of phonologically disordered/delay subjects}

\author{
Ana Paula Ramos de Souza ${ }^{(1)}$, Cristina Blom Sperb ${ }^{(2)}$
}

\begin{abstract}
RESUMO
Objetivo: comparar o desempenho narrativo de grupos de sujeitos com atraso e distúrbio fonológico e controles em aquisição típica. Métodos: foram analisados 63 sujeitos, 32 (50,79\%) com atraso, 12 $(19,04 \%)$ com distúrbio e 19 (30,10\%) em aquisição típica, avaliados e classificados fonologicamente, em produção narrativa pelo instrumento de Zilles e da narrativa inventada, ambas analisadas por tipologia narrativa. Questionários sobre as interações narrativas foram aplicados aos pais e professores. Resultados: foram observadas diferenças estatisticamente significantes entre o grupo com distúrbios e o controle, respectivamente o pior e melhor desempenho. O grupo em aquisição típica demonstrou o melhor desempenho na narrativa livre. Conclusão: a tipologia fonológica apresentou-se parcialmente relacionada com o desempenho narrativo.
\end{abstract}

DESCRITORES: Narração; Fala; Linguagem

\section{INTRODUÇÃO}

Através da fonologia autossegmental ${ }^{1}$, é possível propor uma distinção entre distúrbio e atraso fonológico. $\mathrm{O}$ atraso no desenvolvimento fonológico caracteriza-se pela aplicação de regras naturais em idades nas quais se esperaria que estas não fossem mais aplicadas, enquanto que os desvios caracterizam-se pela ocorrência de regras nãonaturais, envolvendo traços aleatórios na hierarquia, sendo o que define este quadro são os tipos de regras que estão operando no sistema da criança e não mais o fator idade como no caso de atraso. A autora ressalta a troca de traços de classes principais (soante, aproximante) e a inversão de troca de traços (///->/r/) são típicos de desvios. Há autores ${ }^{2}$ que afirmam uma diferença significativa entre a proporção encontrada de Atraso e Distúrbio, pois $29 \%$ das crianças apresentavam Distúrbio Fonológico e $71 \%$ Atraso fonológico, em uma amostra de

(1) Fonoaudióloga; Docente do Departamento de Fonoaudiologia da Universidade Federal de Santa Maria, UFSM, Santa Maria, RS; Doutora em Letras pela Pontifícia Universidade Católica do Rio Grande do Sul.

(2) Fonoaudióloga; Integrante da equipe de profissionais da Associação de Assistência à Criança Deficiente, AACD; Especializanda em Motricidade Orofacial pelo CEFAC Saúde e Educação.

Conflito de interesses: inexistente
88 sujeitos. Decorre desta constatação a necessidade de se questionar o quanto tal distinção é ou não relevante para a pesquisa desta patologia, ou seja, diferenciam-se clinicamente grupos de sujeitos, refletindo-se em distinções na terapêutica dos mesmos. A relevância de tal questão é afirmada na literatura clássica sobre desvio fonológico ${ }^{3}$ ao propor a utilização de uma avaliação precisa dos componentes da língua. $O$ autor também cita trabalhos que demonstram que a classe gramatical influencia na correção fonológica, exemplificando que verbos, conjunções e preposições podem apresentar produção mais incorreta do que substantivos durante a aquisição fonológica. Portanto, a interação entre os componentes gramaticais presentes na construção de frases, sentenças, pode manifestar-se na construção do texto maior, tendo-se como referência para coletá-lo instrumento evocativo ${ }^{4} \mathrm{e}$ tipologia descrita na literatura nacional ${ }^{5}$. $\mathrm{O}$ instrumento evocativo utilizado ${ }^{4}$ consiste de uma sequência de desenhos na qual há um evento introdutório (menina passeando), um desequilíbrio (surgimento de um dragão), conflito (o dragão e a menina lutamela com sarrafos na mão), início da resolução (a menina se tranca ou o dragão a tranca) e final (um homem destranca a menina e fazem uma fogueira com os sarrafos ao redor da qual conversam). Já a tipologia proposta ${ }^{5}$ consiste de cinco tipos: 
I- relato sem tema central: há eventos sem relação entre si.

II - relato com tema central: há eventos com uma relação entre si, mas em modo descritivo

III - narrativa primitiva: há evento introdutório, desequilíbrio e final abrupto (sem resolução).

IV - relativa em cadeia: há evento introdutório, desequilíbrio, desenvolvimento parcial de uma resolução e um final abrupto.

$\mathrm{V}$ - narrativa verdadeira: há evento introdutório, desequilíbrio, desenvolvimento completo da resolução e final bem trabalho, todos elementos ligados de modo lógico e coerente.

$\mathrm{Na}$ literatura internacional, autores ${ }^{6}$ analisam qualitativamente as narrativas de sujeitos com e sem distúrbios de linguagem demonstrando que a extensão da história, o desenvolvimento gramatical e temático estão menos desenvolvidos no grupo com distúrbio do que no grupo em aquisição típica. Tais distinções entre crianças com distúrbios específicos de linguagem e sujeitos em aquisição típica são verificadas em vários estudos sobre a habilidade de definir ${ }^{7}$, ou repetição de palavras em teste competitivo de memória operacional ${ }^{8}$, diferenças em extensão de enunciados (MLU) ${ }^{9}$. Dadas as distinções encontradas afirma-se a necessidade de estratégias terapêuticas específicas ${ }^{10}$ para os distúrbios de linguagem em geral. Especificamente no caso dos distúrbios fonológicos, há vários estudos na literatura nacional que afirmam habilidades processuais menos desenvolvidas, como a memória operacional ${ }^{11,12}$, e a consciência fonológica ${ }^{13}$.

Apesar da distinção entre os sujeitos com e sem distúrbios específicos de linguagem, possivelmente, correlacionar-se a fatores constitucionais e/ ou ambientais dos sujeitos, como atestam alguns trabalhos ${ }^{14}$, em que as condições iniciais dos sujeitos com alterações específicas no desenvolvimento da linguagem parece ser o melhor preditor de sua evolução terapêutica em aspectos gramaticais e pragmáticos. No entanto, cabe ressaltar que a aquisição da habilidade de narrar é fortemente marcada por fatores ambientais, já que demanda uma disponibilidade do adulto para narrar. Tanto a família quanto a escola atuam nesse processo de aquisição que é crescente dos 5 aos 12 anos ${ }^{15}$.

Partindo de tal visão teórica, objetivou-se com esta pesquisa analisar comparativamente o desempenho narrativo de grupos de sujeitos com atraso e distúrbio fonológico e controles em aquisição típica.

\section{MÉTODOS}

Esta pesquisa caracteriza-se como um estudo comparativo, descritivo e transversal com uma população de crianças em aquisição típica e atípica da fonologia. A amostra foi de conveniência, abrangendo o período de Agosto a Novembro de 2004. Nesse período, foram analisadas as narrativas de 32 crianças com atraso fonológico, 12 com distúrbio fonológico, e 19 em aquisição fonológica concluída. As 44 crianças com distúrbio e atraso pertenciam ao banco de dados da Dra. Ana Paula Ramos, inserido no projeto Desvios fonológicos: caracterização, avaliação e terapia.

A coleta de dados iniciou com uma consulta à Secretaria Municipal para acesso à escola e contato com coordenadores para indicarem crianças com distúrbios/atraso fonológico. A estas, assim como aos controles escolhidos, foi enviada carta de esclarecimento aos pais e o termo de consentimento livre e esclarecido (TCLE). Com esses foi utilizado um protocolo de dados sócio-demográficos, planejamento de gravidez e parto do sujeito, evolução psicomotora e linguística e oportunidades de oferta da narrativa (contação de historinhas em casa). Os professores também receberam questionário relacionado a este aspecto em sala de aula. Infelizmente, apenas os dados gerais e o TCLE retornaram e o questionário sobre oferta de narrativa retornou em baixíssimo número o que não permitiu analisá-los neste artigo.

Todas as crianças tiveram seu desenvolvimento e a linguagem avaliados por observação em conversação e atividade livre para confirmar a suspeita de distúrbio de fala e a ausência de grandes transtornos do desenvolvimento bem como outras patologias de linguagem (deficiência mental, autismo, psicose, surdez...). Aquelas cuja hipótese diagnóstica poderia ser distúrbio articulatório de origem fonética e/ou fonológica, foram avaliadas quanto à motricidade orofacial (aspectos como morfologia, funções como respiração, mastigação, deglutição e praxias orofaciais), avaliação fonológica da criança ${ }^{16}$ repetição de palavras e sons para verificação das possibilidades de produção fonética dos fonemas. A seguir solicitou-se que produzissem uma narrativa espontânea (contassem uma história, um filme infantil ou um relato) e foi aplicado o instrumento evocativo da narrativa ${ }^{4}$, que consiste em figuras evocativas sobre a luta entre uma menina e dragão, conforme anteriormente citado.

Os dados fonológicos obtidos foram analisados por uma fonologista experiente, por efetivar a classificação em Distúrbio e Atraso Fonológico de acordo com os critérios de fonológicos autossegmentais ${ }^{1}$.

Depois de classificados os grupos quanto à tipologia fonológica, as narrativas de cada grupo foram analisadas em separado. Os tipos narrativos observados foram: relato, caso, narrativa primitiva, cadeia e narrativa verdadeira ${ }^{5}$. 
Tabela 1 - Tipo de narrativa - Instrumento de Zilles (1992) por grupo

\begin{tabular}{|c|c|c|c|c|c|}
\hline \multirow{2}{*}{ Grupo } & \multicolumn{4}{|c|}{ Tipo de narrativa - Zilles } & \multirow{2}{*}{ Total } \\
\hline & Cadeia & Primitiva & Relato & Verdadeira & \\
\hline \multirow[t]{2}{*}{ Distúrbio } & 1 & 6 & 4 & 1 & 12 \\
\hline & $8,3 \%$ & $50,0 \%$ & $33,3 \%$ & $8,3 \%$ & $100,0 \%$ \\
\hline \multirow[t]{2}{*}{ Atraso } & 10 & 14 & 5 & 3 & 32 \\
\hline & $31,3 \%$ & $43,8 \%$ & $15,6 \%$ & $9,4 \%$ & $100,0 \%$ \\
\hline \multirow[t]{2}{*}{ Normal } & 12 & 3 & & 4 & 19 \\
\hline & $63,2 \%$ & $15,8 \%$ & & $21,1 \%$ & $100,0 \%$ \\
\hline \multirow[t]{2}{*}{ Total } & 23 & 23 & 9 & 8 & 63 \\
\hline & $36,5 \%$ & $36,5 \%$ & $14,3 \%$ & $12,7 \%$ & $100,0 \%$ \\
\hline
\end{tabular}

Valor de $p$ do teste Qui-quadrado $=0,007^{\star *}$

Valores em negrito indicam frequência estatisticamente superior aos demais grupos.

Valores em itálico indicam frequência estatisticamente inferior aos demais grupos.

O projeto foi aprovado pelo Comitê de Ética em Pesquisa da Universidade Luterana do Brasil sob protocolo 107/2002.

O teste utilizado na análise das variáveis foi o Qui-quadrado. Valores de $p$, inferiores ao nível de significância adotado ( $5 \%$ ou 0,050$)$, indicam que há diferença significante entre os grupos. Para entendermos o porquê de o teste ter resultado significativo foi utilizada a medida denominada "Resíduo ajustado". Devido à baixa quantidade de casos em relação ao número de células das tabelas, a significância do teste Qui-quadrado foi obtida por meio de simulações e, a partir desses resíduos, as células que colaboraram para tornar a estatística significativa foram coloridas. O software utilizado foi o SPSS 10.0 para análise estatística e o Excel para confecção dos gráficos.

\section{RESULTADOS}

A Tabela 1 apresenta o tipo de narrativa por grupo. Em relação à amostra analisada, percebese que há um grupo maior de sujeitos com Atraso Fonológico $(50,8 \%)$ do que Distúrbio (19\%) na amostra total de sujeitos analisados nesta pesquisa. A idade média dos sujeitos com distúrbio foi de 7,5 com desvio padrão de 1,24; de atraso de 7,13 com desvio padrão de 0,94 e os sujeitos em aquisição típica apresentaram a idade média de 7,58 com desvio padrão 0,61.

Em relação à escolaridade, houve um percentual maior de sujeitos na primeira série nos grupos com distúrbio $(75 \%)$ e com atraso $(59,4 \%)$. O grupo em aquisição típica apresentou percentual igual na primeira e segunda séries (36,8\%). A idade máxima dos sujeitos foi 10 anos (grupo com distúrbio) e a mínima 5 anos (grupos com atraso e distúrbio). Em termos de escolaridade, a série mais avançada em que se encontravam os sujeitos com distúrbio foi a terceira.

Observa-se que entre os tipos de narrativas mais comuns na amostra, estão a cadeia e a primitiva, conforme é demonstrado na Tabela 1. Nesta tabela, pode-se observar que no grupo de distúrbios há mais narrativas do tipo relato do que cadeia. No grupo normal, percebem-se menos narrativas do tipo primitiva e mais do tipo cadeia. Já no grupo de atraso não há diferença significativa, apresentando um número de narrativas por tipo que não difere estatisticamente dos outros dois grupos. Esse resultado sugere um continuum evolutivo entre os sujeitos com distúrbio, atraso e em aquisição fonológica típica, em que os primeiros apresentam um desempenho narrativo pior e os últimos o melhor.

Isso parece refletir-se em uma baixa iniciativa nos grupos de distúrbio e atraso fonológicos para narrar espontaneamente conforme Tabela 2. Pode-

Tabela 2 - Narrativa Espontânea por grupo

\begin{tabular}{cccc}
\hline \multirow{2}{*}{ Grupo } & \multicolumn{2}{c}{ Narrativa espontânea } & \multirow{2}{*}{ Total } \\
\cline { 2 - 3 } & Não & Sim & \\
\hline Distúrbios & 12 & 0 & 12 \\
& $100,0 \%$ & $0,0 \%$ & $100,0 \%$ \\
\hline Atraso & 27 & 5 & 32 \\
& $84,4 \%$ & $15,6 \%$ & $100,0 \%$ \\
\hline Normal & 0 & 19 & 19 \\
& $0,0 \%$ & $100,00 \%$ & $100,00 \%$ \\
\hline Total & 39 & 24 & 63 \\
& $61,9 \%$ & $38,1 \%$ & $100,0 \%$ \\
\hline
\end{tabular}

Valor de $p$ do teste Qui-quadrado $=0,000^{\star *}$

Valores em negrito indicam frequência estatisticamente superior aos demais grupos.

Valores em itálico indicam frequência inferior aos demais grupos. 
se observar que no grupo de atraso e distúrbio fonológico, existem menos narrativas espontâneas, havendo uma diferença significativa em relação ao grupo controle.

$\mathrm{Na}$ Tabela 3, pode-se observar que as narrativas espontâneas, do tipo verdadeiro, tiveram um maior percentual no grupo sem alteração fonológica, que também apresenta numero maior de narrativas espontâneas verdadeiras $(54,2 \%)$. Esse dado reforça os resultados anteriormente referidos sobre a superioridade de desempenho do grupo de sujeitos sem distúrbio ou atraso fonológico.

Como o retorno dos questionários enviados aos pais e professores foi muito pequeno, não foi possível a realização de análise estatística. Entretanto, as respostas aos poucos questionários recebidos foram sugestivas que as atividades narrativas podem estar tendo uma baixa frequência nos ambientes escolar e familiar, já que sequer são alvo de reflexão, sobretudo por parte dos professores.

Tabela 3 - Tipo de narrativa espontânea por grupo

\begin{tabular}{ccccccc}
\hline \multirow{2}{*}{ Grupo } & \multicolumn{5}{c}{ Tipo da narrativa } & \multirow{2}{*}{ Total } \\
\cline { 2 - 6 } & Caso & Primitiva & Relato & Verdadeira & Versos & \\
\hline Atraso & 1 & & 2 & 1 & 1 & 5 \\
& $20,0 \%$ & & $40,0 \%$ & $20,0 \%$ & $20,0 \%$ & $100,0 \%$ \\
\hline Normal & 2 & 2 & 3 & 12 & & 19 \\
& $10,5 \%$ & $10,5 \%$ & $15,8 \%$ & $63,2 \%$ & & $100,0 \%$ \\
\hline Total & 3 & 2 & 5 & 13 & 1 & 24 \\
& $12,5 \%$ & $8,3 \%$ & $20,8 \%$ & $54,2 \%$ & $4,2 \%$ & $100,0 \%$ \\
\hline
\end{tabular}

Valor de $p$ do teste Qui-quadrado $=0,124$ (não significativo)

Obs.: Os totais referem-se apenas aos casos em que houve relato espontâneo

\section{DISCUSSÃO}

Sabe-se que a tipologia fonológica ${ }^{1}$, que tem como principal característica a organização hierárquica de traços, afirma que no atraso há uma aplicação de regras naturais em idades nas quais se esperaria que estas não fossem mais aplicadas, enquanto que os distúrbios, caracterizam-se pela ocorrência de regras não-naturais, envolvendo traços aleatórios na hierarquia, sendo que o que define este quadro são os tipos de regras que estão operando no sistema da criança e não mais o fator idade, como no caso do atraso. Assim, no distúrbio haveria uma maior alteração do componente fonológico do que no atraso, por esta distinção. A alteração maior no componente fonológico pode ter um efeito nos demais componentes da gramática como afirma a literatura clássica ${ }^{3}$ ao propor que é praticamente impossível uma alteração exclusiva do componente fonológico nos distúrbios fonológicos. Esse fato parece ser confirmado pela alteração estatisticamente inferior no desempenho narrativo do grupo com distúrbio em relação ao grupo em aquisição típica e ao grupo com atraso. No entanto, o grupo com atraso manteve-se em uma faixa de desempenho narrativo intermediário entre os dois outros grupos sem confirmação estatística desta diferença. Esse fato sugere uma confirmação parcial da tipologia, pela análise quantitativa.

Sabe-se da existência de interação entre os componentes gramaticais na construção de enunciados, assim as alterações fonológicas podem prejudicar o planejamento dos enunciados necessários à construção narrativa que demanda muito planejamento semântico e sintático para sua construção. Na narrativa, além da seleção lexical e do tipo frasal, que são traduzidos em um planejamento e execução articulatórios, há a organização de tópicos e comentários do discurso, bem como de elementos como a intencionalidade, progressão, coerência e coesão que são importantes na construção do texto oral para que possa atingir níveis mais elaborados da narrativa ${ }^{6}$.

Esse aspecto parece se relacionar a habilidades processuais menos desenvolvidas nos sujeitos com distúrbio fonológico como a de memória operacional ${ }^{8}$, em geral e do fonológico especificamente ${ }^{11-13}$ da qual tanto a alça fonológica quanto o executivo central são fundamentais para o processamento da linguagem. Enquanto a alça fonológica serve como buffer de entrada da informação auditiva de tipo linguística, o executivo central faz a pesquisa semântica, sendo fundamental para organização de proposições linguísticas. Assim, alterações nesses componentes sugerem uma 
dificuldade tanto na internalização de sequências narrativas como em sua produção por parte dos sujeitos com distúrbio fonológico. O acesso lexical dificultado e o não desenvolvimento adequado de habilidades metalinguísticas fazem parte de um quadro geral dos distúrbios de linguagem ${ }^{7,8}$, em que habilidades lingüísticas como definir ou a memória de sequências linguísticas menos frequentes podem ser menos robustas, dificultando o processamento de palavras, frases e texto em cadeia.

Os resultados desta pesquisa alertam para que o distúrbio fonológico não seja tratado como um problema exclusivamente fonológico, mas se deva estar atento aos processos linguísticos mais gerais em sua terapêutica. Oferecer as oportunidades adequadas de desenvolvimento linguístico aos sujeitos afetados por esse distúrbio implica ir além do planejamento fonológico, como sugerem alguns trabalhos da literatura internacional ${ }^{10}$.

Outra hipótese sugerida a partir dos resultados desta pesquisa, é que haja uma alteração maior na etapa de linguagem em que fonologia e narrativa se resolvem em termos aquisitivos, pois a habilidade de narrar tem sua estrutura básica concluída nas idades em que também se conclui a aquisição do sistema fonológico (5-6 anos), atingindo pico evolutivo aos 12 anos $^{15}$. Esses resultados corroboram o que a literatura consultada apresenta sobre distúrbio fonológico, e sobre distúrbio específico de linguagem. Esta afirma haver distinções entre os sujeitos com e sem distúrbios na habilidade narrativa ${ }^{6}$, entre outras habilidades de processamento linguístico ${ }^{7,8}$.

É importante pontuar, no entanto, que isso não implica em afirmar a determinação exclusiva de uma alteração biológica ou inata dos sujeitos já que habilidades, além de possível pré-disposição biológica ${ }^{14}$, são frutos de interações sociais, em especial a habilidade de narrar ${ }^{5}$. Pode-se observar, pelos resultados dos questionários dos pais e professores, que não há um interesse sobre o tema o que sugere uma investigação específica sobre como se está ou não proporcionando interações narrativas em casa e na escola. Possivelmente o desempenho geral inferior à narrativa verdadeira (esperada ao redor de 5-6 anos de idade em ambiente estimulantes, sugere pouca prática nesse tipo de atividade no grupo estudado. Parece, portanto, tratar-se de uma situação complexa do ponto de vista social, na qual o distúrbio induz a uma certa dificuldade e talvez falta de investimento do interlocutor e este, circularmente, favorece a permanência do distúrbio. Sabe-se que o incentivo a narrar e a tornar-se um falante ativo e atento é fundamental tanto no processo terapêutico como no de escolarização desses sujeitos para que sua inclusão social se dê. Se a escola e família não favorecer tais habilidades com a intensidade necessária, com certeza, os sujeitos portadores de distúrbios fonológicos serão os mais prejudicados evolutivamente tanto na aquisição da linguagem oral e escrita quanto nas interações sociais que dela decorrem.

Essa evolução linguístico-discursiva mais precária também se confirma na maior falta de disposição do grupo com distúrbio do que o grupo com atraso e, sobretudo, do que o grupo em aquisição fonológica típica, para narrar espontaneamente, sem instrumento para evocação. Possivelmente a menor experiência ou qualidade no narrar ${ }^{5}$ esteja fazendo a diferença entre os grupos quando se trata de produzir uma narrativa espontânea. Hipotetizase que a mesma deva estar mais prejudicada nos sujeitos com distúrbios pela própria dificuldade de interação verbal com os mesmos, já que sua fala pode ser mais ininteligível ${ }^{2}$ do que a dos demais grupos.

Em relação às faixas etárias de cada grupo, podese perceber que a média fica em 7 anos, embora os sujeitos mais velhos (10 anos) estejam na categoria distúrbio. Esses resultados parecem confirmar as afirmações da literatura ${ }^{1,2}$ sobre o distúrbio fonológico poder atingir até 10 anos, e que dos 5 aos 7 anos a categoria atraso é muito frequente.

Um aspecto a ser ressaltado é que a proporção de sujeitos com atraso e com distúrbio na amostra geral estudada no projeto de pesquisa mais amplo (88 sujeitos) mantém a mesma proporção percentual de atraso (70\%) e distúrbio (30\%) referida na literatura ${ }^{2}$. A expressividade numérica da diferença na prevalência dos dois tipos propostos na literatura ${ }^{1}$ e as distinções no desempenho narrativo, indicam que tal distinção não deva ser totalmente desprezada em termos clínicos. Ressalta-se que pode ser tomada como um reflexo da interação entre componentes da gramática ${ }^{3}$ no processo de aquisição da linguagem e, principalmente, como fruto de carências de interações linguísticas nos ambientes familiar e escolar, conforme afirma a literatura ${ }^{5}$, e atestam os resultados deste trabalho.

As implicações clínicas deste trabalho são: a necessidade de investigar profundamente todos os aspectos gramaticais e discursivos dos sujeitos com distúrbio/atraso fonológico, não deixando em segundo plano a evolução narrativa já que se trata de um aspecto importante da aquisição da linguagem oral e de interface entre a oralidade e a escrita pelo caráter letrado que a constitui. 
A distinção atraso/distúrbio merece uma continuidade de estudos para analisar sua relevância clinica. Será que a mesma se reflete em evoluções terapêuticas distintas? Ou há uma similaridade terapêutica evolutiva entre os sujeitos com atraso/distúrbio? Os resultados desta pesquisa sugerem não descartar, ao menos por enquanto, tal distinção e considerar a possibilidade de se investir na competência/desempenho narrativo durante o processo terapêutico.

\section{CONCLUSÃO}

Através dos resultados e discussão da pesquisa pode-se concluir que as crianças do grupo com distúrbio difere em seu discurso narrativo do grupo controle através de diferença estatisticamente significante, o que demonstra uma relação parcial entre o desempenho narrativo e a tipologia fonológica estudada.

\section{ABSTRACT}

Purpose: to compare the narrative performance subject groups with delay and disturbance and controls in typical acquisition. Methods: 63 subjects were analyzed, 32 (50.79\%) with delay, $12(19.04 \%)$ with disturbance and $19(30.10 \%)$ in typical acquisition, and appraised and classified phonologically, in narrative production through the instrument of Zilles and the invented narrative, both analyzed through narrative typology. Questionnaires about the narrative interactions were applied to the parents and teachers. Results: significant statistical differences were noted between the group with disturbances and the control group, the worst and best performance, respectively. The group in typical acquisition demonstrated the best performance in free narrative. Conclusion: the phonological typology was partially related with the narrative performance.

KEYWORDS: Narration; Speech; Language

\section{REFERÊNCIAS}

1. Lamprecht R. A aquisição fonológica normal e com desvios fonológicos evolutivos: aspectos quanto à natureza da diferença. Letras de Hoje. 1995; 30(4):117-25.

2. Ramos APF, Pergher GL, Marques J, Collares LM, Carreirão L. Distúrbio fonológico: perfil fonológico e inteligibilidade de fala. Cad Pesq Ling. 2005; 1 : 67-79.

3. Schwartz RG. Interações entre os componentes da língua no desenvolvimento normal e com desvios. In: Yavas MS, organizador. Desvios fonológicos em crianças: teoria, pesquisa e tratamento. Porto Alegre: Mercado Aberto; 1990.

4. Zilles AM. A ordenação de sujeito, verbo e objeto no discurso narrativo de crianças de 4 a 6 anos. [tese] Porto Alegre (RS): Pontifícia Universidade Católica do Rio Grande do Sul; 1992. 520p.

5. Chesini IM, Ramos APF. Análise comparativa do desenvolvimento narrativo de crianças de 4 a 6 anos de duas escolas com concepções pedagógicas distintas. Fono Atual. 2004; 7(27):21-31.

6. Newman RM, McGregor KK. Teachers and laypersons discern quality differences between narratives produced by children with and without SLI. J Speech Lang Hear Res. 2006; 49(5): 1022-36.
7. Marinellie SA, Johnson CJ. Definitional skill in school-age children with specific language impairment. J Commun Disord. 2002; 35(3): 241-59.

8. Mainela-Arnold E, Evans JL. Beyond capacity limitations: determinants of word recall performance on verbal working memory span tasks in children with SLI. J Speech Lang Hear Res. 2005; 48(4): 897-909.

9. Hewitt LE, Hammer CS, Yont KM, Tomblin JB. Language sampling for kindergarten children with and without SLI: mean length of utterance, IPSYN and NDW. J Commun Disord. 2005; 38(3):197-213. 10. Ebbels SH, Van Der Lely HKJ, Dockrell JE. Intervention for verb argument structure in children, with persistent SLI: a randomized control trial. J Speech Lang Hear Res. 2007; 50(5):1330-49.

11. Linassi LZ, Keske-Soares M, Mota HB. Habilidades de memória de trabalho e o grau de severidade do desvio fonológico. Pró-Fono. 2005; 17(3):383-92.

12. Linassi LZ, Keske-Soares M, Mota HB. Memória de trabalho em crianças com desvio fonológico. Pró-Fono. 2004; 16(1):75-82.

13. Vieira MG, Mota HB, Keske-Soares M. Relação entre idade, grau de severidade do desvio fonológico e consciência fonológica. Rev Soc Bras Fonoaudiol. 2004; 9(3):144-50. 
14. Befi-Lopes DM, Puglisi ML, Rodrigues A, Giusti E, Gândara JP, Araújo K. Perfil comunicativo de crianças com alterações específicas no desenvolvimento da linguagem: caracterização longitudinal das habilidades pragmáticas. Rev Soc Bras Fonoaudiol. 2007; 12(4):265-73
15. Ukrainetz TA, Justice LM, Kaderavek JN, EisenbergSL, GillamRB, HarmHM. Thedevelopment of expressive elaboration in fictional narratives. $J$ Speech Lang Hear Res. 2005; 48(6):1363-77.

16. Yavas MS, Lamprecht RR, Hernandorena CLM. Avaliação fonológica da criança. Porto Alegre: Artmed; 1991.

DOI: 10.1590/S1516-18462009005000039

RECEBIDO EM: 09/01/2008

ACEITO EM: 27/01/2009

Endereço para correspondência:

Ana Paula Ramos de Souza

Rua Raposo Tavares, 134 ap. 401

Santa Maria - RS

CEP: 97015-560 